\title{
Prediksi Website Design Quality dan Service Quality terhadap Repurchase Intention Pada Pelanggan Shopee di Jakarta Dengan Customer Trust Sebagai Mediasi
}

\author{
Melissa Priscillia dan Herlina Budiono \\ Program Studi Manajemen Fakultas Ekonomi dan Bisnis \\ Universitas Tarumanagara \\ E-mail: melissapriscilliaw@yahoo.com
}

\begin{abstract}
This study aims to analyze and know about the impact of website design quality and service quality are the predictor to customer trust, whether customer trust is predictor to repurchase intention, whether website design quality and service quality are predictor to repurchase intention through customer trust on Shopee website customers in Jakarta. This study used 170 samples selected using convenience sampling techniques, where the selected sample were of Shopee's customers in Jakarta. The data collection technique was carried out using a questionnaire. Data were analyzed using PLS-SEM. The result of this research is that website design quality and service quality may positively predict customer trust, customer trust may positively predict repurchase intention, website design quality and service quality may positively predict repurchase intention through customer trust.
\end{abstract}

Keywords: Website Design Quality, Service Quality, Customer Trust, Repurchase Intention

Abstrak: Tujuan penelitian ini adalah untuk mengetahui apakah kualitas desain situs web dan kualitas layanan merupakan prediktor terhadap kepercayaan pelanggan, apakah kepercayaan pelanggan merupakan prediktor terhadap niat beli kembali, apakah kualitas desain situs web dan kualitas layanan merupakan prediktor terhadap niat beli kembali melalui kepercayaan pelanggan pada pelanggan situs web Shopee di Jakarta. Penelitian ini menggunakan 170 sampel yang dipilih dengan menggunakan teknik convenience sampling, dimana sampel yang dipilih adalah pelanggan situs web Shopee di Jakarta. Teknik pengambilan data dilakukan dengan menggunakan kuesioner. Data dianalisis dengan menggunakan PLS-SEM. Hasil penelitian ini adalah apakah kualitas desain situs web dan kualitas layanan dapat memprediksi secara positif kepercayaan pelanggan, kepercayaan pelanggan dapat memprediksi secara positif niat beli kembali, apakah kualitas desain situs web dan kualitas layanan dapat memprediksi secara positif niat beli kembali melalui kepercayaan pelanggan.

Kata Kunci: Kualitas desain situs web, kualitas layanan, kepercayaan pelanggan, niat beli kembali

\section{LATAR BELAKANG}

Seiring berjalannya waktu, teknologi dan informasi berkembang semakin pesat, salah satunya adalah teknologi internet. Internet menjadi bagian penting dalam berbagai aspek kehidupan, salah satunya gaya hidup masyarakat yang menjadi serba praktis dan mudah. Hal tersebut tentu memunculkan ide para pebisnis untuk menjadikan internet sebagai salah satu sarana untuk menjual dan mempromosikan produknya secara online yang di kenal dengan istilah electronic commerce atau e-commerce. E-commerce di definisikan sebagai transaksi komersial yang melibatkan pertukaran nilai yang dilakukan melalui atau menggunakan teknologi digital antara individu dengan individu lainnya (Laudon \& Traver, 2017: 8-9). 
E-commerce memiliki beberapa perbedaan jika dibandingkan dengan bisnis tradisional (traditional commerce). Pada konsep traditional commerce, pembeli dan penjual akan bertemu dan berinteraksi secara langsung (direct interaction) di pasar, toko, atau tempat usaha lainnya (Zhou, Lu, \& Wang, 2009 dalam Nicholas Wilson \& Keni, 2018). Sedangkan dalam konsep $e$ commerce, penjual (seller) dan pembeli (buyer) tidak bertemu secara langsung, melainkan, pertemuan kedua belah pihak dijembatani sebuah website tempat kedua belah pihak akan melakukan transaksi dan apabila pembeli tertarik dan yakin, maka pembeli dapat membeli produk tersebut dari website tersebut (Moon, Sultana, \& Nur, 2017; Zhou et al., 2009 dalam Nicholas Wilson \& Keni, 2018).

Repurchase intention merupakan salah satu faktor penting di dalam bidang pemasaran, karena repurchase intention mampu meningkatkan profitabilitas perusahaan yang lebih signifikan karena pembelian berulang akan menghasilkan konsumen yang loyal. (Goh et al., 2016). Website design quality merupakan salah satu faktor yang dapat mempengaruhi repurchase intention. semakin baik kualitas disain pada website sebuah bisnis e-commerce maka semakin besar kemungkinan konsumen melakukan pembelian kembali pada website tersebut. Shin et al., (2013) dalam Tandon, Kiran, \& Sah (2017). Service quality menjadi salah satu aspek yang penting untuk diperhatikan dan dipahami, Menurut Zhou et al. (2009) dalam Nicholas Wilson \& Keni (2018), kualitas jasa dapat menentukan apakah pelanggan akan melakukan pembelian kembali pada laman yang sama di masa mendatang atau tidak. Customer trust merupakan salah satu faktor yang dapat mempengaruhi repurchase intention.

\section{KAJIAN TEORI}

\section{Gambaran Umum Teori}

Teori yang digunakan dalam penelitian ini adalah Theory of Reasoned Action (TPA) dan Theory of Planned Behaviour (TPB). Theory of Reasoned Action (TPA) merupakan teori yang menjelaskan perilaku manusia melalui pertimbangan dari segala informasi yang ada dan memberikan dampak kepada perilaku individu atas apa yang dilakukan. Teori ini menyatakan bahwa sikap yang mempengaruhi suatu perilaku melalui suatu proses pengambilan keputusan yang teliti dan memiliki alasan. Theory of Planned Behaviour (TPB) Ajzen (1991) menjelaskan perilaku manusia dan menjelaskan bagaimana hubungannya terhadap kepercayaan serta perilaku. Teori ini merupakan pengembangan dari Theory of Reasoned Action (TRA) yang mencakup ukuran kontrol keyakinan dan kontrol perilaku (Armitage \& Conner, 2001:471). Komponen dalam Theory of Planned Behavior (TPB) ada tiga yaitu Atitude Towards the Behavior (sikap terhadap perilaku), Subjective Norm (norma subjektif) dan Perceived Behavioural Control (kontrol perilaku persepsi). Berikut ini adalah gambar dari model Theory of Planned Behaviour (TPB).

Website Design Quality. adalah evaluasi pengguna terhadap fitur situs web seperti mudah digunakan, tata letak, navigasi, informasi dan kesesuaian situs web dengan preferensi konsumen. Aladwani \& Palvia 2002:469; Wakefield et al., 2004 dalam K. A. Bahari, D. Abdullah dkk. 2018; Barnes \& Vidgen, 2002; Alhabsyi \& Dien Mardhiyah, 2018; Agag \& ElMasry, 2016 dalam Hamida Abd El Samie Mohamed \& Mahmoud Rammadan Al-Azab, 2017).

Service quality. adalah keseluruhan penilaian yang dibentuk oleh evaluasi konsumen terhadap layanan yang diterima (Inegbenebor 2006, dalam Simon Ayo Adekunle and Jones O. Ejechi 2018; Eshghi, et al., 2008 dalam Simon Ayo Adekunle \& Jones O. Ejechi 2018; Nguyen Ngoc Duy Phuong \& Tran Thi Dai Trang 2018; Lin, 2007 dalam Chiung-Ju Liang \& Hui-Ju Chen 2009; Zeithaml, 1988 dalam Leonnard dkk. 2017). 
Customer Trust. adalah kesediaan konsumen terhadap pihak lain dengan harapan bahwa pihak lain akan memberikan produk atau layanan yang dijanjikan. (Nischay K. Upamannyu dkk, 2015; Mayer et al., 1995 dalam Shrawan Kumar Trivedi 2018; Agustin \& Singh 2015, dalam Richard Chinomona 2013; McCard 2002, dalam Nurhanan Syafiah Abdul Razak dkk., 2014; Kotler \& Keller, 2016:225; Mowen \& Minor, 2002:322).

Repurchase Intention. adalah keputusan untuk melakukan pembelian kembali akan suatu produk atau jasa sebanyak dua kali atau lebih dengan merek yang sama. (Bayraktar et al. 2012, dalam Chih-Cheng Volcic Chen \& Chih-Jou Chen, 2017; Chen et al. 2010:16, dalam Johanna Nilsson \& Olle Wall 2017; Rajaobelina \& Bergeron 2009, dalam Simon Ayo Adekunle \& Jones O. Ejechi, 2018; Retno Setyorini \& Rizky Prima Nugraha, 2016; Rahmad Wijaya dkk., 2018).

Kaitan antara website design quality dengan customer trust. Marko Tatang \& Mudiantono (2017) menyatakan bahwa adanya pengaruh positif antara website design quality dengan trust. Website design quality yang berkualitas tinggi memberikan kenyamanan kepada konsumen sehingga membuat konsumen merasa percaya pada laman tersebut. Menurut I Gede Yogi Pramana Ni Made Rastini (2016) Kepercayaan mencerminkan harapan yang positif satu pihak untuk perilaku kepada orang lain di masa depan. Situs web berkualitas tinggi menunjukkan kemampuan vendor dan minatnya yang tulus pada pelanggannya, sehingga akan mempengaruhi kepercayaan konsumen terhadap perusahaan tersebut.

Kaitan antara service quality dengan customer trust. Nurhadi \& Asriel Azis (2018) meneliti hubungan antara service quality terhadap trust dan customer loyalty dan menyatakan service quality menyatakan bahwa adanya pengaruh positif antara service quality dengan trust. konsumen yang percaya terhadap vendor akan menggantungkan dirinya karena adanya jaminan dari kualitas pelayanan yang bagus, sebaliknya konsumen yang tidak percaya terhadap perusahaan tidak akan menggantungkan dirinya dikarenakan tidak adanya jaminan akan kualitas pelayanan yang bagus.

Kaitan antara customer trust dengan repurchase intention. Indah Puspitasari \& Vita Briliana (2017) meneliti hubungan antara perceived ease of use, perceived usefulness, trust dan perceived enjoyment terhadap repurchase intention dan menyatakan bahwa trust memiliki pengaruh positif terhadap repurchase intention. Menurut Retno Setyorini \& Rizky Prima Nugraha (2016) kepercayaan dipandang sebagai elemen kunci untuk membangun kesuksesan perusahaan. Tanpa kepercayaan, perusahaan akan sulit untuk membangun hubungan jangka panjang dengan para pelanggannya. Penelitian yang dilakukan oleh Retno Setyorini \& Rizky Prima Nugraha (2016) sejalan dengan penelitian yang dilakukan oleh Rahmad Wijaya dkk., (2018) yang menyatakan customer trust memiliki pengaruh positif terhadap repurchase intention.

Customer trust memediasi hubungan antara website design quality dengan repurchase intention. Nicholas Wilson \& Keni (2018) meneliti hubungan antara website design quality dan service quality terhadap repurchase intention melalui trust sebagai variabel mediasi dan menyatakan trust memediasi hubungan antara website design quality, service quality, dan repurchase intention. Jae Ik Shin dkk. (2013) menyatakan bahwa semakin tinggi persepsi konsumen tentang situs e-commerce, semakin tinggi niat konsumen untuk berbelanja kembali di situs web tersebut melalui kepercayaan yang di rasakannya.

Customer trust memediasi hubungan antara service quality dengan repurchase intention. Jae Ik Shin dkk. (2013) meneliti hubungan antara site quality terhadap repurchase intention 
melalui mediasi dan menyatakan bahwa site quality dapat mempengaruhi repurchase intention dengan meningkatkan atau melemahkan customer satisfaction, customer trust, dan commitment pelanggan dalam situasi transaksi online. Leonnard dkk. (2017), Keputusan konsumen untuk membeli kembali niat tergantung pada evaluasi kualitas layanan yang mereka terima. Jika evaluasi kualitas layanan melebihi harapan konsumen, maka konsumen akan membeli kembali layanan tersebut, sebaliknya jika evaluasi kualitas layanan lebih rendah dari ekspektasi konsumen, hal itu akan memberikan efek sebaliknya.

Kaitan website design quality dengan repurchase intention. Abhishek Tandon (2020) meneliti hubungan antara EWOM, website quality dan product satisfaction terhadap customer satisfaction dan repurchase intention dan menyatakan bahwa adanya pengaruh positif antara website design quality terhadap repurchase intention. Cheung et al., \& Cheung \& Lee (2005) dalam Innocentius Bernarto dkk. (2019) menyatakan ketika suatu website mampu bekerja dengan baik, dimana dalam hal ini suatu website dapat dengan mudah dipahami dan digunakan oleh pelanggan, maka kualitas dari website tersebut dapat meningkatkan kepercayaan pelanggan terhadap website dan perusahaan, dimana di dalam hal ini, website yang memiliki tampilan dan kualitas yang baik mampu mencerminkan bahwa perusahaan tersebut juga memiliki reputasi yang baik.

Kaitan service quality dengan repurchase intention. I Wayan Angga Wiradarma \& $\mathrm{Ni}$ Nyoman Rsi Respati (2020) meneliti hubungan antara service quality dan customer satisfaction terhadap repurchase intention dan menyatakan adanya pengaruh positif antara service quality dan repurchase intention. Tingkat kepuasan menyebabkan pelanggan memiliki keinginan yang semakin kuat untuk mengulang pembelian. Pengulangan pembelian dilakukan ketika konsumen merasa semua apa yang diharapkan terpenuhi sehingga konsumen memiliki rasa ingin untuk melakukan pembelian berikutnya dari produk atau layanan tersebut.

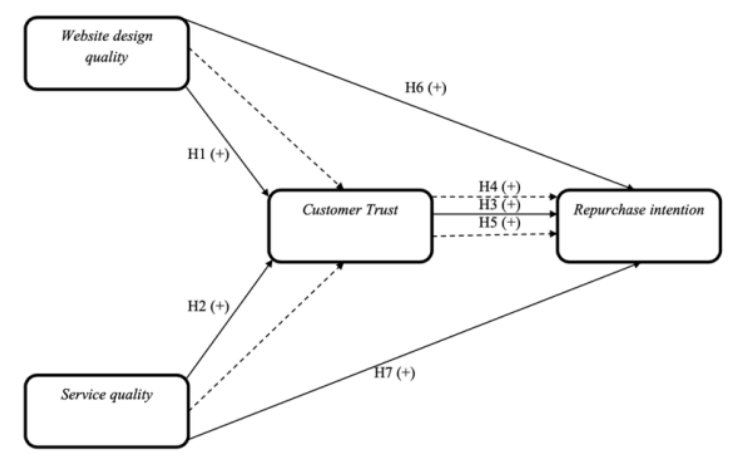

Gambar 1. Model Penelitian

$\mathrm{H}_{1}$ : Website design quality merupakan prediktor positif untuk customer trust pada pelanggan situs web Shopee di Jakarta.

$\mathrm{H}_{2}$ : Service quality merupakan prediktor positif untuk customer trust pada pelanggan situs web Shopee di Jakarta.

$\mathrm{H}_{3}$ : Customer trust merupakan prediktor positif untuk repurchase intention pada pelanggan situs web Shopee di Jakarta.

$\mathrm{H}_{4}$ : Customer trust dapat memediasi prediksi website design quality terhadap repurchase intention pelanggan situs web Shopee.co.id di Jakarta.

$\mathrm{H}_{5}$ : Customer trust dapat memediasi prediksi service quality terhadap repurchase intention pelanggan situs web Shopee.co.id di Jakarta. 
$\mathrm{H}_{6}$ : Website design quality merupakan prediktor positif untuk repurchase intention pada pelanggan situs web Shopee di Jakarta.

$\mathrm{H}_{7}$ : Service quality merupakan prediktor positif untuk repurchase intention pada pelanggan situs web Shopee di Jakarta.

\section{METODOLOGI}

Sampel penelitian ini adalah sebanyak 170 responden pelanggan Shopee di Jakarta yang pernah melakukan transaksi Shopee, dengan convenience sampling, dimana pada penelitian ini sampel yang diteliti adalah responden yang pernah melakukan transaksi di Shopee. Pada penelitian ini desain penelitiannya adalah desain penelitian deskriptif, dimana penelitian ini dilakukan satu kali saja. Instrument pada penelitian ini dengan menggunakan kuesioner. Pengukuran variabel-variabel dalam penelitian ini mengacu pada penelitian sebelumnya antara lain sebagai berikut:

Variabel

Website Design Quality

Service Quality

Customer Trust
20 item

5 item

\section{Indikator}

5 item

Repurchase Intention 3 item

\section{Acuan}

Yi Liu (2018); Jae Ik Shin, et al. (2013);Urvashi Tandon, dkk. (2017);Tao Zhou (2009)

Tao Zhou (2009); Richard
Chinomona (2013)

Indah Puspitasari \& Vita Briliana (2017); Tao Zhou, dkk (2009); Rahmad Wijaya, dkk. (2018)

Yi Liu (2018); Jae Ik Shin, et al. (2013); Leonnard, dkk (2017); Ni Made Purnami \& Nyoman Nurcaya (2015)

\section{HASIL UJI STATISTIK}

Berdasarkan jenis kelamin, mayoritas responden merupakan wanita $(54,7 \%)$, dan sisanya merupakan pria (45,3\%). Berdasarkan usia, mayoritas responden berusia 31 - 40 tahun dengan jumlah sebanyak 65 orang $(38,2 \%)$, responden yang berusia 21 - 30 tahun sebanyak 63 orang $(37,1 \%)$, reponden yang berusia $>40$ tahun sebanyak 28 orang $(16,5 \%)$ dan responden yang berusia $<20$ tahun sebanyak 14 orang $(8,2 \%)$. Dari 170 responden, diketahui bahwa sebagian besar responden dalam penelitian ini merupakan pegawai swasta sebanyak 56 orang $(32,9 \%)$, pegawai swasta sebanyak 55 orang $(32,4 \%)$, pegawai negeri sebanyak 31 orang $(18,2 \%)$, dan mahasiswa sebanyak 28 orang (16,5\%). Dari 170 responden, diketahui bahwa mayoritas responden yang tinggal di Jakarta Barat sebanyak 57 orang $(33,5 \%)$ dan Jakarta Timur sebanyak 57 orang (33,5\%), Jakarta Selatan 25 orang $(14,7 \%)$, Jakarta Pusat 20 orang $(11,8 \%)$, Jakarta Utara 11 orang (6.5\%). Dari 170 responden, dapat diperoleh bahwa sebagian responden yang memiliki pengeluaran setiap bulan diatas Rp. 10.000 .000 sebanyak 100 orang $(58,8 \%)$, Rp. 5.000.000 s/d Rp. 10.000.000 sebanyak 52 orang (30,6\%), dan dibawah Rp. 5.000.000 sebanyak 18 orang $(10,6 \%)$. Sebagian besar responden yang berbelanja secara online dalam sebulan diatas 6 kali sebanyak 81 orang $(59,1 \%), 2$ - 5 kali sebanyak 51 orang $(37,2 \%)$, dan satu kali sebanyak 5 orang $(3,6 \%)$. 
Hasil uji validitas baik validitas konvergen maupun validitas diskriminan telah dilakukan melalui besaran nilai Average Variance Extracted (AVE) yang lebih besar dari 0,5 $(>0,5)$, loading factor yang lebih besar dari 0,7 (>0,7), Fornell-Larcker, dan cross loadings. Penelitian ini pengujian reliabilitas juga telah dilakukan dengan mengukur besaran nilai composite reliability dan besaran nilai cronbach's alpha yang lebih besar dari 0,6 (>0,6). $\mathrm{R}^{2}$ digunakan untuk mengukur seberapa besar variabel website design quality, service quality mempengaruhi customer trust dan seberapa besar variabel website design quality, service quality mempengaruhi repurchase intention. $R$ square untuk variabel mediasi customer trust adalah sebesar 0,489 artinya sebesar 48,9\% variabel customer trust dapat dijelaskan website design quality dan service quality, kemudian sisanya sebesarnya $51,5 \%$ dapat dijelaskan oleh faktorfaktor yang lainnya seperti customer satistaction, repurchase behavior dan lain-lain. Selanjutnya terdapat nilai $R$ square sebesar $0,506 \%$ artinya $50,6 \%$ dari variabel repurchase intention dapat dijelaskan oleh website design quality dan repurchase intention. Kemudian sisanya sebesar $49,4 \%$ dapat dijelaskan oleh variabel-variabel lain yang tidak diteliti dalam penelitian ini seperti price, perceived usefulness dan lain-lain. Kemampuan website design quality, service quality untuk menjelaskan variabel mediasi customer trust dapat terbilang lemah dan kemampuan website design quality, service quality untuk menjelaskan repurchase intention terbilang sedang. Selanjutnya, hasil pengujian $\mathrm{Q}^{2}$ untuk customer trust menunjukan nilai sebesar 0,410 dan untuk repurchase intention sebesar 0,433 yang artinya nilai predictive relevance $\left(\mathrm{Q}^{2}\right)$ dalam penelitian ini lebih besar dari 0 (nol).

Tabel 1. Hasil Rekapitulasi Pengujian Hipotesis

\begin{tabular}{|l|c|c|c|c|}
\hline Hipotesis & $\boldsymbol{\beta}$ & $\boldsymbol{p}$-value & $\mathbf{f}^{\mathbf{2}}$ & Keterangan \\
\hline $\begin{array}{l}\mathrm{H}_{1}: \text { Website Design Quality } \rightarrow \text { Customer } \\
\text { Trust }\end{array}$ & 0,318 & 0,005 & 0,013 & Tidak Ditolak \\
\hline $\mathrm{H}_{2}:$ Service quality $\rightarrow$ Customer Trust & 0,462 & 0,000 & 0,273 & Tidak Ditolak \\
\hline $\begin{array}{l}\mathrm{H}_{3}: \text { Customer Trust } \rightarrow \text { Repurchase } \\
\text { Intention }\end{array}$ & 0,711 & 0,000 & 1,023 & Tidak Ditolak \\
\hline $\begin{array}{l}\mathrm{H}_{4}: \text { Website Design Quality } \rightarrow \\
\text { Customer Trust } \rightarrow \text { Repurchase } \\
\text { Intention }\end{array}$ & 0,226 & 0,013 & & Tidak Ditolak \\
\hline $\begin{array}{l}\mathrm{H}_{5}: \text { Service Quality } \rightarrow \text { Customer Trust } \\
\rightarrow \text { Repurchase Intention }\end{array}$ & 0,329 & 0,000 & & Tidak Ditolak \\
\hline $\begin{array}{l}\mathrm{H}_{6}: \text { Website Design } \rightarrow \text { Quality } \\
\text { Repurchase Intention. }\end{array}$ & 0,226 & 0,013 & & Tidak Ditolak \\
\hline $\begin{array}{l}\mathrm{H}_{7}: \text { Service Quality } \rightarrow \text { Repurchase } \\
\text { Intention. }\end{array}$ & 0,329 & 0,000 & & Tidak Ditolak \\
\hline
\end{tabular}

Pada hasil pengujian hipotesis 1 di atas menunjukkan bahwa website design quality merupakan prediktor positif, signifikan, dan memiliki efek yang kuat untuk customer trust. Hal ini menunjukkan bahwa $\mathrm{H}_{1}$ tidak ditolak. Pada hasil pengujian hipotesis 2 di atas menunjukkan bahwa service quality merupakan prediktor positif, signifikan, dan memiliki efek yang kuat untuk repurchase intention. Hal ini menunjukkan bahwa $\mathrm{H}_{2}$ tidak ditolak. Pada hasil pengujian hipotesis 3 di atas menunjukkan bahwa customer trust merupakan prediktor positif, signifikan, dan memiliki efek kuat untuk repurchase intention. Hal ini menunjukkan bahwa $\mathrm{H}_{3}$ tidak ditolak. Pada hasil pengujian hipotesis 4 di atas menunjukkan bahwa website design quality merupakan prediktor positif dan signifikan untuk repurchase intention melalui customer trust. Hal ini menunjukkan bahwa $\mathrm{H}_{4}$ tidak ditolak. Pada hasil pengujian hipotesis 5 di atas menunjukkan bahwa service quality merupakan prediktor positif dan signifikan untuk repurchase intention melalui customer trust. Hal ini menunjukkan bahwa $\mathrm{H}_{5}$ tidak ditolak. 
Pada hasil pengujian hipotesis 6 di atas menunjukkan bahwa website design quality merupakan prediktor positif dan signifikan untuk repurchase intention. Hal ini menunjukkan bahwa $\mathrm{H}_{6}$ tidak ditolak. Pada hasil pengujian hipotesis 7 di atas menunjukkan bahwa service quality merupakan prediktor positif dan signifikan untuk repurchase intention. Hal ini menunjukkan bahwa $\mathrm{H}_{7}$ tidak ditolak.

\section{DISKUSI}

Pada hasil pengujian hipotesis pertama $\left(\mathrm{H}_{1}\right)$ menunjukkan bahwa website design quality merupakan prediktor positif untuk customer trust. Hasil pengujian hipotesis ini sejalan dengan penelitian yang dilakukan oleh Marko Tatang \& Mudiantono (2017) yang menyatakan bahwa website design quality merupakan prediktor positif untuk customer trust. Menurut Zhou et al. (2009) dalam Nicholas Wilson \& Keni (2018) semakin baik kualitas desain pada website sebuah bisnis e-commerce maka semakin besar kemungkinan konsumen melakukan pembelian kembali pada lama tersebut. Pada hasil pengujian hipotesis kedua Menurut Leonnardo dkk. (2017), keputusan konsumen untuk membeli kembali niat tergantung pada evaluasi kualitas layanan yang mereka terima. Jika evaluasi kualitas layanan melebihi harapan konsumen, maka konsumen akan membeli kembali layanan tersebut, sebaliknya jika evaluasi kualitas layanan lebih rendah dari ekspektasi konsumen, hal itu akan memberikan efek sebaliknya. Pada hipotesis kedua $\left(\mathrm{H}_{2}\right)$ menunjukan bahwa service quality berpengaruh positif terhadap customer trust. Hasil pengujian hipotesis ini sejalan dengan penelitian yang dilakukan oleh Nurhadi \& Asriel Azis (2018). Service quality maksimal yang diberikan Shopee akan menciptakan nilai yang lebih bagi pelanggan sehingga akan membuat pelanggan merasa pengalaman yang berbeda dari e-commerce lainnya. Tentunya pelanggan akan merasa senang ketika Shopee memberikan layanan yang lebih dari apa yang mereka terima dari e-commerce lain. Selain itu, pelanggan akan merasa percaya ketika apa yang mereka harapkan diberikan oleh Shopee. Sebaliknya, apabila service quality yang diberikan Shopee tidak dapat memenuhi harapan pelanggan, maka pelanggan akan merasa tidak percaya dan hal tersebut dapat menimbulkan masalah bagi Shopee, sehingga Shopee diharapkan mempertahankan dan meningkatkan service quality yang telah ada. Pada hipotesis ketiga $\left(\mathrm{H}_{3}\right)$ menunjukan bahwa customer trust berpengaruh positif terhadap repurchase intention. Hasil pengujian hipotesis ini sejalan dengan penelitian yang dilakukan oleh Indah Puspitasari \& Vita Briliana (2017). Repurchase intention tentu dapat terjadi karena kepercayaan pelanggan kepada suatu brand. Semakin percaya pelanggan terhadap suatu brand, maka semakin terikat pelanggan dengan brand tersebut. Sehingga sangat penting bagi Shopee untuk selalu mengedepankan Customer Trust. Ketika pelanggan sudah cocok dengan brand yang digunakan, mereka cenderung menggunakan layanan tersebut di masa yang akan datang karena kepercayaan pelanggan terhadap brand tersebut sudah terbentuk.Pada hipotesis keempat $\left(\mathrm{H}_{4}\right)$ menunjukan bahwa customer trust dapat memediasi hubungan antara website design quality terhadap repurchase intention. Hasil pengujian hipotesis ini sejalan dengan penelitian yang dilakukan oleh Jae Ik Shin dkk. (2013). Ketika pelanggan merasa cocok dan nyaman dengan suatu brand maka mereka cenderung enggan untuk berpindah ke brand lain. Repurchase intention tentu dapat terjadi karena kepercayaan pelanggan kepada suatu brand. Semakin percaya pelanggan terhadap suatu brand, maka semakin terikat pelanggan dengan brand tersebut. Sehingga sangat penting bagi Shopee untuk selalu mengedepankan customer trust. Ketika pelanggan sudah cocok dengan brand yang digunakan, mereka cenderung menggunakan layanan tersebut di masa yang akan datang karena kepercayaan pelanggan terhadap brand tersebut sudah terbentuk. Tampilan website yang menarik dan baik akan menimbulkan kenyamanan dan kesenangan saat menggunakannya. Kenyamanan dan kesenangan yang dirasakan setelah menggunakan website tersebut dapat menimbulkan kepercayaan. Kepercayaan tersebut dapat dijadikan faktor yang kuat bagi pelanggan untuk menggunakan layanan Shopee kembali di masa yang akan datang 
secara terus menerus sehingga enggan berpindah atau mencoba situs web belanja lainnya. Pada hasil pengujian hipotesis kelima $\left(\mathrm{H}_{5}\right)$ menunjukkan bahwa customer trust dapat memediasi hubungan antara service quality terhadap repurchase intention. Hasil pengujian hipotesis ini sejalan dengan penelitian yang dilakukan oleh Tao Zhou (2009). Dalam meningkatkan repurchase intention, Shopee harus meningkatkan pelayanan yang diberikan agar pelanggan merasakan sendiri bagaimana pengalaman mereka setelah berbelanja di Shopee. Setelah melakukan transaksi pelanggan pasti menilai layanan yang diberikan Shopee. Hanya ada 2 penilaian yaitu baik atau buruk. Penilaian yang baik akan menimbulkan kepercayaan kepada Shopee sehingga melakukan repurchase intention. Sebaliknya, ketika pelanggan memberikan penilaian yang buruk pelanggan tidak akan percaya pada Shopee dan tidak akan berbelanja di masa yang akan datang. Pada hasil pengujian hipotesis keenam $\left(\left(\mathrm{H}_{6}\right)\right.$ website design quality berpengaruh positif terhadap repurchase intention. Hasil pengujian hipotesis ini sejalan dengan penelitian yang dilakukan oleh Abhishek Tandon (2020). E-commerce atau toko online harus memperhatikan website design quality mereka dan harus sesuai dengan persepsi mereka sehingga pelanggan akan melakukan pembelian kembali pada situs web tersebut. Seringkali pelanggan kurang mendapatkan informasi dari tampilan website maka Shopee diharapkan dapat mempertahankan dan meningkatkan kualitas website yang sudah baik. Pada hasil pengujian hipotesis ketujuh $\left(\left(\mathrm{H}_{7}\right)\right.$ menunjukan bahwa service quality berpengaruh positif terhadap repurchase intention. Hasil pengujian hipotesis ini sejalan dengan penelitian yang dilakukan oleh I Wayan Angga Wiradarma \& Ni Nyoman Rsi Respati (2020). service quality merupakan salah satu faktor yang penting dalam mempengaruhi repurchase intention. Kehandalan Shopee dalam memberikan layanan dalam menanggapi keluhan konsumen dapat membuat pelanggan melakukan pembelian ulang, setia kepada perusahaan dan akan merekomendasikan kepada orang lain.

\section{PENUTUP}

Berdasarkan analisis hipotesis yang telah dilakukan, dapat disimpulkan bahwa website design quality dan service quality merupakan prediktor positif untuk repurchase intention dan melalui customer trust sebagai mediasi. Penelitian ini memiliki keterbatasan yaitu jumlah sampel yang diteliti masih terbatas yaitu sebanyak 170 orang, sampel masih sebatas wilayah Jakarta variabel yang diteliti masih sebatas website design quality, service quality, customer trust, dan repurchase intention, dan masih ada beberapa kekeliruan dalam penulisan, serta menganalisis variabel yang terkait dalam penelitian ini. Beberapa saran untuk penelitian selanjutnya adalah agar dapat menggunakan jumlah sampel yang lebih dari 170 orang, dapat memperluas ruang lingkup sampel yang digunakan, dan agar dapat menambah variabel atau mengganti variabel yang lainnya (yang memiliki pengaruh lebih besar terhadap repurchase intention) selain variabel yang digunakan pada penelitian ini.

Website design quality dan service quality memiliki peranan paling penting dalam repurchase intention situs web Shopee. Semakin tinggi tingkat kepuasan atas kualitas web dan kepuasan atas layanan yang diberikan terhadap suatu brand, semakin terikat pelanggan dengan brand tersebut. Website design quality dan service quality terjadi karena terdapat pengalaman yang menyenangkan ketika mendapatkan layanan yang baik. Sekali pelanggan telah merasa puas dengan apa yang diberikan dan cocok dengan brand yang digunakan, pelanggan akan cenderung menggunakan layanan tersebut di masa yang akan dating.

Customer trust memegang peranan paling penting dalam memediasi hubungan antara website design quality dan service quality repurchase intention situs web Shopee. Peneliti menyarankan bahwa Shopee harus menjaga kepercayaan konsumen terhadap Shopee dengan memperhatikan dan meningkatkan tampilan situs web, agar produk tersebut semakin dipercayai memiliki kinerja yang baik oleh pelanggan, sehingga menimbulkan sikap konsumen 
yang positif terhadap suatu brand sehingga konsummen memiliki keinginan untuk melakukan pembelian kembali dimasa yang akan datang.

\section{DAFTAR PUSTAKA}

Adekunle, S., A., \& Ejechi, J. O. (2018). Modelling Repurchase Intention Among Smartphones Users in Nigeria. Journal of Modelling in Management, 13(4),794-814.

Ajzen, I. (1991). The Theory of Planned Behavior. Organizational Behavior And Human Decision Processes, 50, 179-211.

Aladwani, A., \& Palvia, P. (2002). Developing and Validating an Instrument for Measuring User Perceived Web Quality. Information and Management, 39(6), 467-476.

Alhabsyi, S., \& Mardhiyah, D. (2018). The Influence of Website Trust on Recommendation Adoption and Word-of-Mouth Communication: Study on TripAdvisor Website. International Conference of Organizational Innovation, 1301-1313.

Bahari, K., A., Abdullah, D., \& Kamal, S. B. M. (2018). The Influence Of Hotel Website Design Quality, Perceived Ease Of Use and Perceived Usefulness on Loyalty Intention. The Turkish Online Journal of Design, Art and Communication - TOJDAC, 701-710.

Barnes, S., J., \& Vidgen, R.T. (2002). Assessing E-Commerce Quality with WebQual: An Evaluation of the Usability, Information Quality, and Interaction Quality of Internet Bookstores. Journal of Electronic Commerce Research, 3, 114-127.

Bernarto, I., Wilson, N., \& Suryawan, I.N. (2019). Pengaruh Website Design Quality, Service Quality, Trust dan Satisfaction Terhadap Repurchase Intention (Studi Kasus: tokopedia.com). Jurnal Manajemen Indonesia, 19(1), 80-90.

Chen, C., C., V., \& Chen, C.-J. (2017). The role of customer participation for enhancing repurchase intention. Management Decision, 55(3), 547-562.

Chinomona., R. (2013). Brand Service Quality, Satisfaction, Trust and Preference as Predictors of Consumer Brand Loyalty in the Retailing Industry. Mediterranean Journal of Social Sciences, 4(14).

Goh, S. K., Hak, M.F.A., Tee, P. L. (2016). Determinants of Smartphone Repeat Purchase Intention Among Malaysians : A Moderations Role of Social Influence and a Mediating Effect of Consumer Satisfaction. Internal Review of Management \& Marketing, 6(4), 993-1004.

Kotler, P., \& Keller, K. L (2016) Marketing Management, 15th Edition, Pearson Education,Inc.

Laudon, K. C., \& Traver, C. G. (2017). E-Comerce 2016 business, tecnology, society (12th ed.). England: Britis Library Cataloguint-in.

Liang, C. -J., \& Chen, H. -J. (2009). A study of the impacts of website quality on customer relationship performance. Total Quality Management \& Business Excellence, 20(9), 971-988.

Liu, Y., \& Tang, X. (2018). The effects of online trust-building mechanisms on trust and repurchase intentions: An empirical study on eBay. Information Tecnology \& People, 31(3), 666-687.

Leonnardo., Comm. M., \& Thung, F. (2017). The Relationship Of Service Quality, Word-OfMouth, And Repurchase Intention in Online Transportation Services. (JPMNT) Journal.

Mohamed, H. A. E. S., \& Al-Azab, M. R. (2017). Exploring Key Factors That Influence Consumer Trust in Airline Websites. Journal of Association of Arab Universities for Tourism and Hospitality, 14(1).

Mowen, J. C., \& Minor, M. (2002) Perilaku Konsumen. Jakarta : Erlangga. 
Nilsson., J., \& Olle Wall, O. (2017). Online customer experience, satisfaction and repurchase intention for online clothing retailing. Master of Science in Marketing and Consumption, 1-22.

Nurhadi \& Azis, A. (2018). Pengaruh Kualitas Pelayanan Terhadap Kepercayaan dan Kesetiaan Konsumen. Jurnal Economia. 14(1).

Phuong, N. N. D., \& Trang, T. T. D. (2018). Repurchase Intention: The Effect of Service Quality, System Quality, Information Quality, and Customer Satisfaction as Mediating

Pramana, I. G. Y., \& Ni Made Rastini, N. M. (2016) Pengaruh Kualitas Pelayanan Terhadap Kepercayaan Nasabah dan Loyalitas Nasabah Bank Mandiri Cabang Veteran Denpasar Bali. E-Jurnal Manajemen Unud, 5(1), 706-733.

Role: A PLS Approach of M-Commerce Ride Hailing Service in Vietnam. Marketing and Branding Research, 5, 78-91.

Purnami, N. M., \& I Nyoman Nurcaya, I. N. (2015). Pengaruh E-Trust, Perceived Usefulness dan E-Satisfaction Terhadap Online Repurchase Intention. Seminar Nasional Sains dan Teknologi, 1, 139-173.

Puspitasari, I., \& Briliana, V. (2017). Pengaruh Perceived Ease-Of-Use, Perceived Usefulness, Trust dan Perceived Enjoyment Terhadap Repurchase Intention (Studi Kasus Pada Website Zalora Indonesia). Jurnal Bisnis dan Akuntansi, 19(2) 171-182.

Razak, N., S., A., Marimuthu, M., Omar, A., \& Mamat, M. (2014). Trust and Repurchase Intention on Online Tourism Services among Malaysian Consumers. Procedia - Social and Behavioral Sciences, 130, 577-582.

Setyorini, R., \& Nugraha, R. P. (2016). The Effect of Trust Towards Online Repurchase Intention with Perceived Usefulness As An Intervening Variable: A Study on KASKUS Marketplace Customers. The Asian Journal of Technology Management, 9(1), 1-7.

Shin, J. I., Chung, K. H., Oh, J. S., \& Lee, C. W. (2013). The effect of site quality on repurchase intention in Internet shopping through mediating variables: The case of university students in South Korea. International Journal of Information Management, 33(3), 453-463.

Tandon, A., Aakash, A., \& Aggarwal, A. G. (2020). Impact of EWOM, website quality, and product satisfaction on customer satisfaction and repurchase intention: moderating role of shipping and handling. International Journal of System Assurance Engineering and Management. 1-8.

Tandon, U., Kiran, R., \& Sah, A. N. (2017). Customer Satisfaction as Mediator Between Website Service Quality and Repurchase Intention: An Emerging Economy Case. Service Science, 9(2), 106-120.

Tatang, M., \& Mudiantono. (2017). The Impact of Website Design Quality, Service Quality, and Enjoyment on Repurchase Intention through Satisfaction and Trust (A Case of Zalora.co.id). Diponegoro Journal of Management, 6(4), 1-11.

Trivedi, S., K., \& Yadav, M. (2018). Predicting online repurchase intentions with eSatisfaction as mediator: a study on Gen Y. VINE Journal of Information and Knowledge Management Systems.

Upamannyu, N. K., Gulati, C., Chack, A., \& Kaur, G. (2015). The Effect Of Customer Trust on Customer Loyalty and Repurchase Intention: The Moderating Influence of Perceived CSR. International Journal of Research in IT, Management and Engineering, 5(4).

Wijaya, R., Farida, Naili., \& Andriyansyah. (2018). Determinants of Repurchase Intentions at Online Stores in Indonesia. International Journal of E-Business Research, 14(3).

Wilson, N. \& Keni. (2018). Pengaruh Website Design Quality dan Kualitas Jasa terhadap Repurchase Intention: Variabel Trust sebagai Variabel Mediasi. Jurnal Manajemen dan Pemasaran Jasa,11(2), 291-310. 
Wiradarma, I. W. A., \& Respati, N. N. R. (2020). PERAN CUSTOMER SATISFACTION MEMEDIASI PENGARUH SERVICE QUALITY TERHADAP REPURCHASE INTENTION PADA PENGGUNA LAZADA DI DENPASAR. E-Jurnal Manajemen, 9(2), 637-657.

Zhou, T., Lu, Y., \& Wang, B. (2009). The Relative Importance of Website Design Quality and Service Quality in Determining Consumers' Online Repurchase Behavior. Information Systems Management, 26(4), 327-337. 